\title{
Toxic encephalopathy due to ingestion of bismuth salts: clinical and EEG studies of 45 patients
}

\author{
V.S U P I N O - V I T E R B O,C.S I C A R D, M. R IS V E G L I A T O, \\ G. RA NCUREL, A N D A. BUGE
}

From the Neurosurgery EEG Laboratory and Departments of EEG and Clinical Neurology, Salpétrière Hospital, and Department of Clinical Neurology, Bicêtre Hospital, Paris, France

S U M MARY Forty-five patients taking bismuth subnitrate orally for therapeutic reasons were admitted to hospital with a myoclonic encephalopathy of acute onset. The clinical features were similar, mostly with mental confusion, disorder of walking and standing, dysarthria, and myoclonic jerks. In 31 cases the EEG showed a characteristic pattern, not previously recognised, which assisted differential diagnosis.

A possible relationship between insoluble bismuth salts oral intake and neurological symptoms was mentioned for the first time by Morrow (1973) in a letter to the Editor of the Australian Medical Journal. The clinical aspects have been accurately described by Burns et al. (1974) in Australia and by Buge et al. (1974a,b) and Buge and Rancurel (1975) in France. A large number of patients admitted to hospital with toxic encephalopathy due to therapeutic ingestion of bismuth salts gave us the opportunity to study the clinical symptomatology in detail and to carry out serial EEG studies which provided useful data in the diagnosis of this encephalopathy.

\section{Patients and methods}

The present study deals with 45 patients, 39 from the Salpétrière Hospital and six from the Bicêtre Hospital, in Paris. There were eight male patients aged from 44 to 70 years, and 37 females aged from 24 to 82 years. All these patients had been treated with an insoluble bismuth salt (subnitrate) 5 to $20 \mathrm{~g}$ daily over a period ranging from four weeks to 30 years. The therapeutic indication was the presence of a colon disorder with constipation often coexisting with dolicho-megacolon. Three patients were pregnant, respectively of eight months, five months, and six weeks duration (constipation, a therapeutic indication for bismuth subnitrate, is frequent in pregnancy).

Address for reprint requests: Dr V. Supino-Viterbo, 76 Bis rue des Saintes Pères, Paris 7, France.

Accepted 18 March 1977
Bismuth blood levels, sampled on the same day as the EEG, ranged from 150 to 1600 micrograms/ litre (normal being less than $20 \mu \mathrm{g} / \mathrm{l}$ ); levels from 200 to $9600 \mu \mathrm{g} / 1$ were found in the urine and 10 to $100 \mu \mathrm{g} / 1$ in the CSF. The three pregnant patients delivered normal babies: in one case bismuth was estimated in the umbilical venous blood and was found to be $250 \mu \mathrm{g} / \mathrm{l}$.

The EEG was recorded with standard equipment at a time constant of $0.3 \mathrm{~s}$. The paper speed was $15 \mathrm{~mm} \mathrm{~s}^{-1}$. The amplification varied between

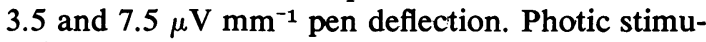
lation was always carried out but overbreathing could be performed only by patients able to cooperate.

\section{Results}

Two clinical phases can be distinguished. A first insidious period lasts from one week to several months during which there is a gradual onset of non-specific symptoms: depression, anxiety, irritability, and even delusions of persecution (two cases) or phobias which may be wrongly interpreted if there is no knowledge of bismuth intake. Often patients are asthenic, somnolent, and unable to carry out positive action but in other cases motor agitation with euphoria may be prominent. All these symptoms can coexist or follow each other in various combinations. Sleep disorder may occur with prolonged insomnia (30 cases), oneiric and often visual hallucinations, with anorexia or more rarely, voracity.

Aggravation of the primary intestinal trouble often induces the subject to increase the dose of 
bismuth and this may be followed by further toxic effects with disorders of affect, memory, and attention as well as inability to plan non-automatic activities, resembling the behaviour in frontal lobe syndromes. Fifteen patients complained of headache. Sometimes in this phase there is already an obviously unsteady gait, motor incoordination with alteration of writing and speech, jerky movements of varying severity. If this phase lasts a long time and there are no gross neurological signs, the subject is of ten referred to a psychiatrist.

The second phase of confirmed encephalopathy takes place abruptly in 24 to 48 hours. Of the various symptoms, four are constant and of considerable diagnostic value: mental confusion, pseudo-tremor accompanied by myoclonic jerks, dysarthria, and disturbances of walking and standing. The mental confusion is of variable severity, sometimes reaching stupor or 'reactive' coma. A dysphoric or euphoric mood was present in about $30 \%$ of cases. If the patient is conscious there is often disorientation in space and time as well as memory, perception, and attention difficulties, with the impossibility of carrying out simple instructions. Sphincteric incontinence is frequent (24 cases) but this does not parallel the severity of confusion. Myoclonic jerks are always present if the patient is carefully examined and represent one of the main symptoms of these encephalopathies. Sometimes they predominate in the upper limbs and distally, while at other times they are diffuse and involve the facial and axial muscles. They are increased by voluntary movements and by stimuli (change of positions, noises, and so on). Tremor in the maintenance of posture has been recorded. Dysarthria is of variable severity. Disturbances of walking and standing can amount to astasia-abasia and seem to be due to the concurrence of axial myoclonic jerks, cerebellar static disturbance, and some disorder of higher cortical functions as observed in the frontal lobe symptomatology. Other symptoms are less common. Disturbances of muscular tone were found in 17 cases (hypotonia being more common). Convulsive seizures were observed in 14 patients, combined with partial crisis in three.

In 31 patients a particular EEG pattern was seen with monomorphic waves at 3 to $5 \mathrm{~Hz}$ involving both temporo-rolandic and frontal areas, unaffected by eye-opening (when the patient was able to cooperate). This rhythm often spread to the occipital regions, while the alpha rhythm had disappeared (Figs. 1 and 2). In most patients there was also a diffuse beta rhythm of low voltage. No spikes or other paroxysmal features appeared in the EEG even during myoclonic jerks, confirming the observations of Gastaut et al. (1975). The EEG features were often very similar in spite of different blood levels of bismuth ranging from 150 to $1600 \mu \mathrm{g} / \mathrm{l}$. However, blood levels may not

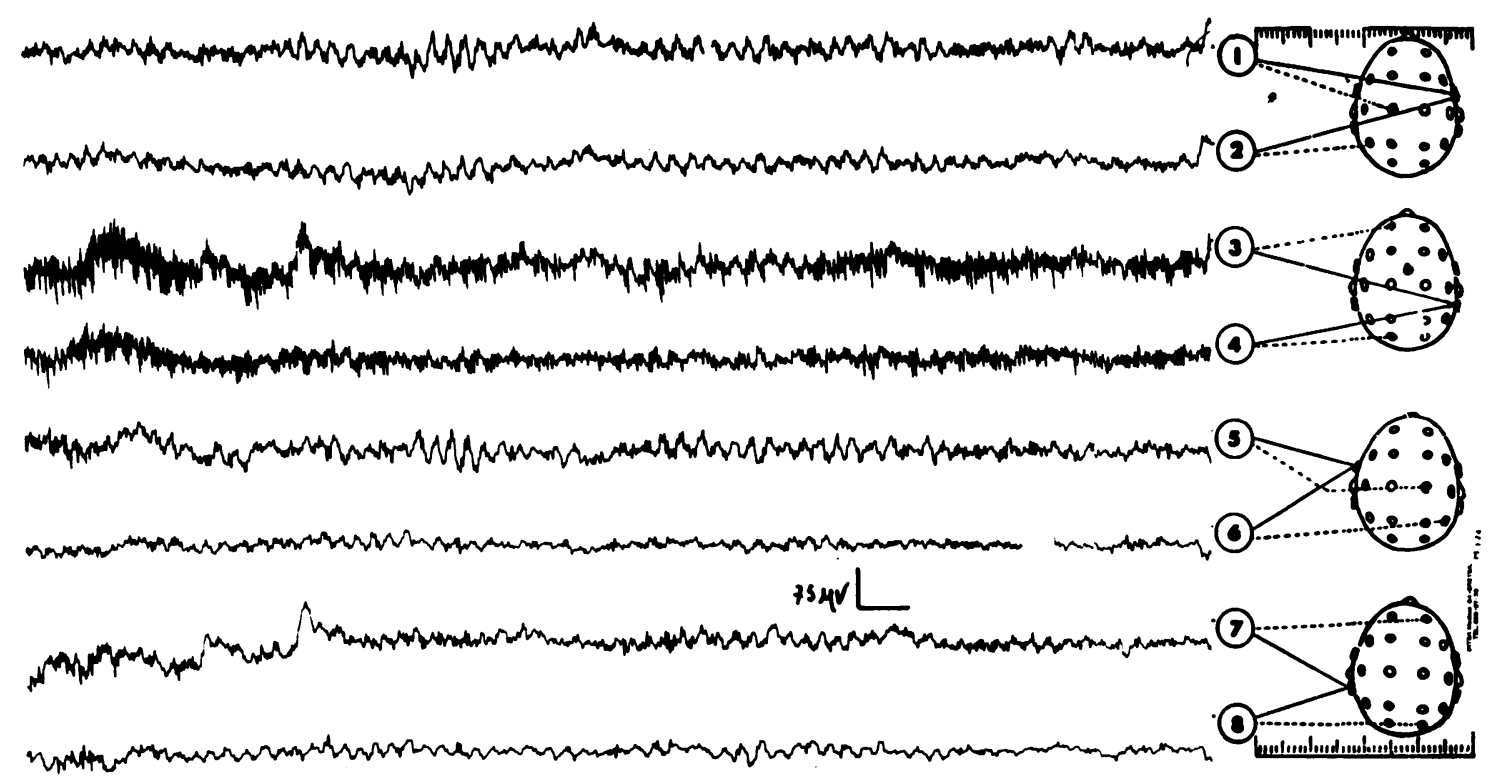

Fig. 1 Predominant 4-5 Hz activity in the EEG of a 33 year old woman with a bismuth blood level of $1600 \mu \mathrm{g} / \mathrm{l}$. Calibrations $75 \mu \mathrm{V}$ and $1.5 \mathrm{~s}$. 


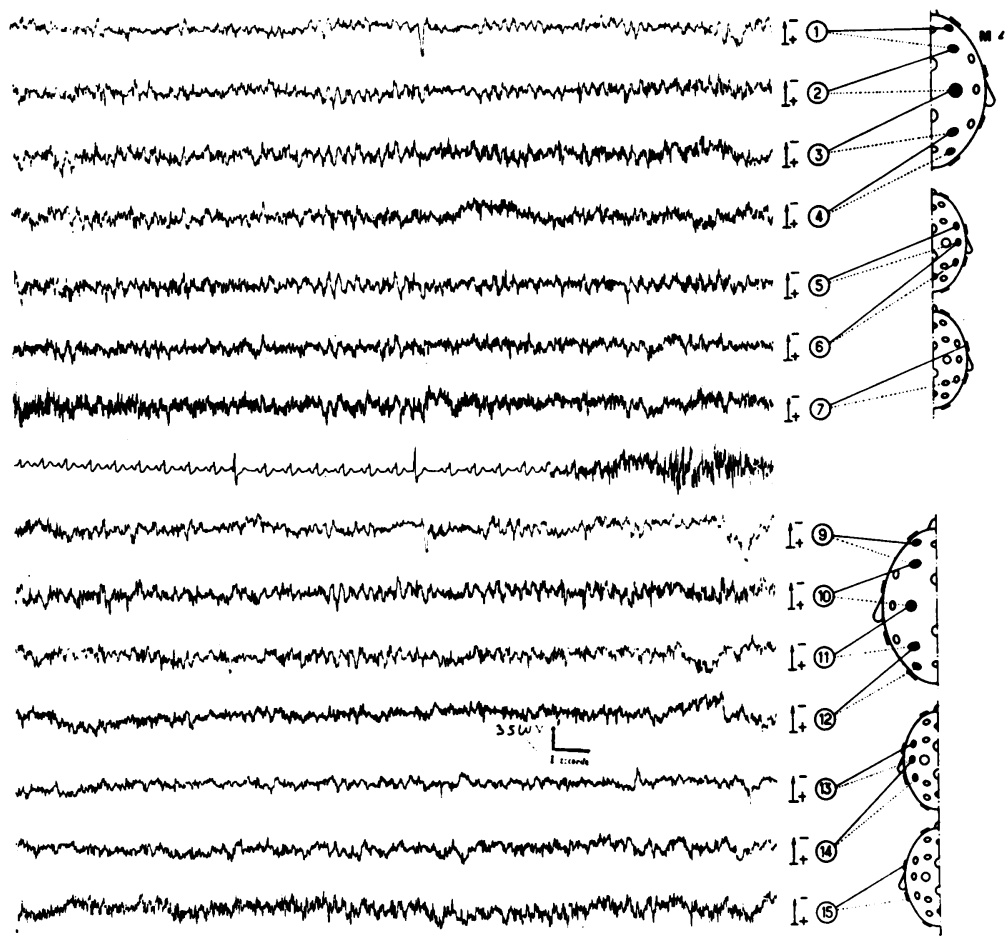

Fig. 2 EEG activity at 5-6 $\mathrm{Hz}$ in a 47 year old woman with a bismuth blood level of $540 \mu \mathrm{g} / \mathrm{l}$. Calibrations $35 \mu \mathrm{V}$ and $1.5 \mathrm{~s}$.

faithfully represent concentrations at tissue level in the brain. This is in accord with anatomopathological data (Escourolle et al., 1977).

The EEG features described above do not always appear immediately. In three subjects the first record showed more irregular slow activity, while more typical features appeared over a few days. Moreover, 14 patients never had typical EEG features.

There were no responses to photic stimulation in the majority of our patients, who, however, complained about the flashes of light (one of our patients reported recently that he was not able to watch television, even after leaving the hospital). Photic stimulation increased myoclonic jerks (when present), but no paroxysmal features were ever observed in the EEG. In one case, photic stimulation induced a convulsive seizure with recruiting bilateral spikes, at first bi-occipital, then diffuse. Clinically the seizures consisted of turning of the head to the right and raising of the left arm, followed by generalised clonic movements. An identical clinical seizure occurred spontaneously in another patient.

Further clinical and EEG studies of 28 patients with typical EEG patterns were made after the peak of the illness and during recovery, with the reappearance of normal features over a period of two weeks to three months. Nevertheless in eight patients with or without typical EEG findings initially, there was a subsequent appearance of diffuse slow waves: the morphology of these waves was very variable, sometimes coexisting with a transitory worsening of consciousness, but in other patients instead there was clinical improvement. This subsequent EEG worsening can be ascribed to different reasons. In four cases there was dilatation of cerebral ventricles and a reduced isotopic transit with contamination due to abnormal reabsorption. In another case dehydration occurred with hypokalaemia. Seizures had occurred in two other patients. Finally, one patient showed simultaneous deterioration of EEG (Fig. 3) and state of consciousness, while his arterial blood ammonia was found to be moderately high ( $44 \mu \mathrm{mol} / \mathrm{l}$; $75 \mu \mathrm{g} / \mathrm{dl})$.

\section{Discussion}

Electroencephalographic features similar to those reported in the present paper have been mentioned in preliminary observations by some of us (Buge et al., 1974a,b; Buge and Rancurel, 1975) and by other authors (Lhermitte et al., 1975; Loiseau et al., 1975). However, the number of cases at the time was too small to realise that the EEG 


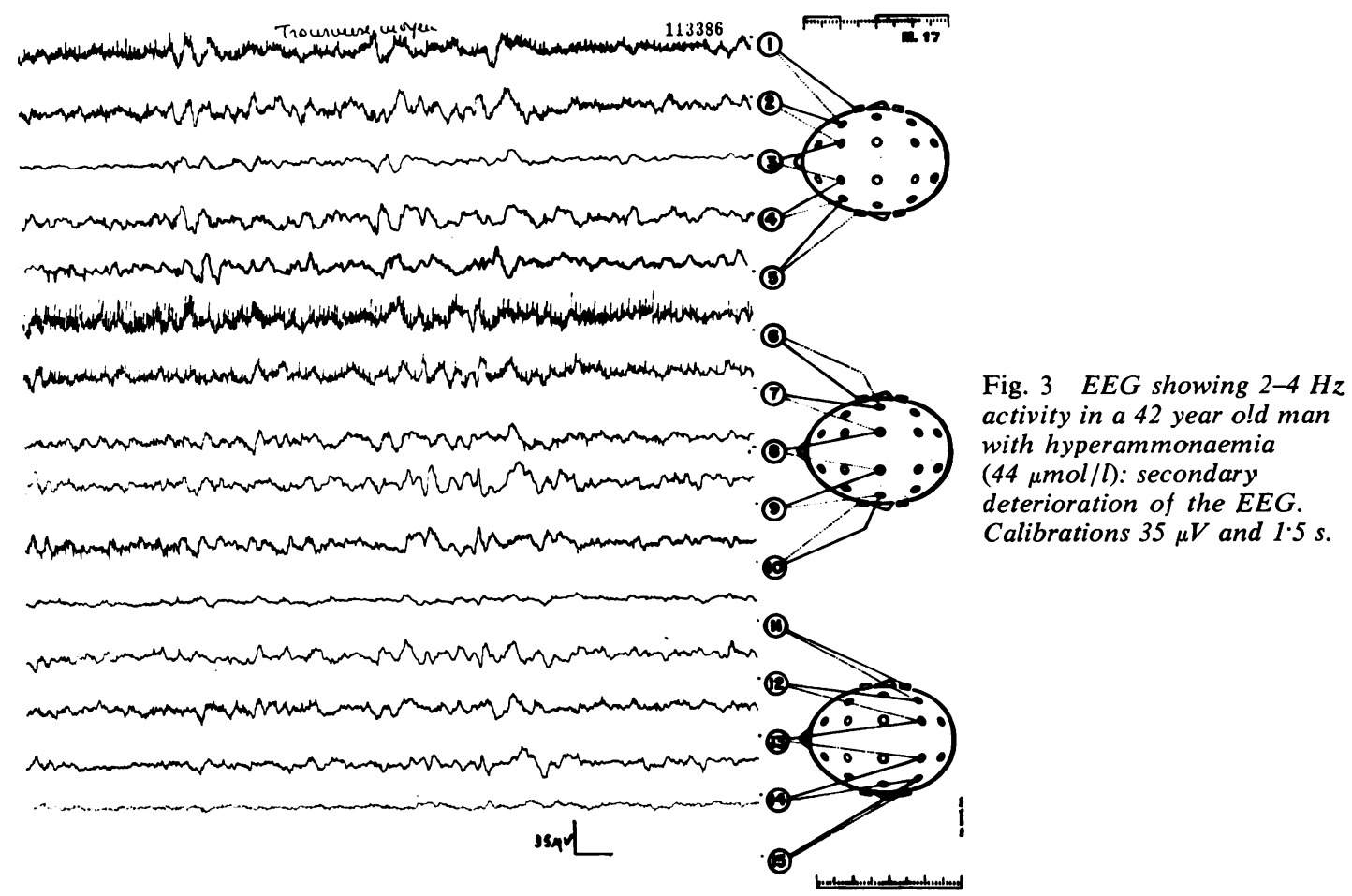

patterns are characteristic of this type of encephalopathy and fairly constant during the acute phase (31 patients out of 45 in the present study).

Particularly useful data were provided by the EEG in the differential diagnosis with JakobCreutzfeldt's disease because the absence of the periodic EEG features described by Jones and Nevin (1954), Pallis and Spillane (1957), and Alema and Bignami (1959) made it possible to exclude this condition.

In a few cases Alzheimer's disease was considered on clinical grounds but the EEG features as described by Letemendia and Pampiglione (1958) and Gaches (1973) and the responses to photic stimulation were different from those seen in our patients. In three of our cases there was a lateralised or focal EEG abnormality and some unilateral motor impairment was found in one of them. These features, however, were transitory, and the suspicion of a tumour was soon eliminated and there were no sequelae.

Most of the patients with this encephalopathy recovered from three to 12 weeks after interruption of bismuth administration. In a few cases some disorder of behaviour or memory persisted for a longer period, although it was difficult to assess its relation to the encephalopathy because most of the patients were already known to be neurotic and none of them had been seen by us before their relatively acute illness due to bismuth.

Three patients died in the acute phase of the encephalopathy, and various cerebral structures were sampled in order to assess the bismuth concentration in the tissue. The highest levels were found in the frontal and occipital cortex, in the thalamus and in the cerebellum, reaching $25 \mathrm{mg} /$ kg. As control, the bismuth levels were studied in the brain of patients who died because of other illnesses (such as Jakob-Creutzfeldt disease) and values of $0.010 \mathrm{mg} / \mathrm{kg}$ brain weight were found (Escourolle et al., 1977). High intracerebral levels of bismuth were also found in other patients who had recovered from bismuth encephalopathy but who died later of an unrelated illness and after their blood level had returned to normal values.

It is surprising that bismuth encephalopathy has been observed only in Australia (where 22 cases were described) and in France where a much larger number has been studied. An epidemiological INSERM study by Martin-Bouyer (1976) on 294 patients in various regions of France suggested that all bismuth compounds are responsible even if the 'heavy' subnitrate is the most toxic. No other associated drugs seem to play any role in this encephalopathy. There is no direct relation between the level of bismuth consumption (highest 
in the south-east of France) and the number of intoxications observed in various regions of France. In fact the first reported cases came from the west and north-west of France (where bismuth consumption is lowest) and spread gradually to the rest of the country. The distribution in time and space of the reported cases of encephalopathy gave the impression of an epidemic disease.

According to Goujet (personal communication) and Professor Simon's team at the Pitie Hospital, Paris, this is not a toxic phenomenon directly proportional to bismuth consumption. These authors believe that there is some modification of the intestinal flora. In fact it has been demonstrated that certain microorganisms are able to dissolve metals (mercury or lead). They believe that bismuth administered as an insoluble substance would become soluble and pass through the bloodbrain barrier, perhaps because of a cerebral tropism. Sollmann and Seifter (1939) gave a soluble salt of bismuth (trimethyl bismuth) to experimental animals and observed toxic phenomena similar to the neurological symptoms of bismuth encephalopathy in man. This might lend support to the hypothesis that the reputed insoluble bismuth salts in the gut may be rendered soluble and reach the brain, with rapid appearance of the clinical phenomena with high concentrations of bismuth in particular regions of the central nervous system in man.

We thank Dr H. P. Cathala and Dr J. Gaches for access to their data as well as Dr G. Pampiglione for his valuable suggestions.

\section{References}

Alema, G., and Bignami, A. (1959). Polio-encenfalopatia degenerativa subacuta del presenio con stupore acinetico e rigidità decorticata con mioclonie varieta 'mioclonica' della malattia di Jakob-Creutzfeldt). Rivista Sperimentale di Freniatria e Medicina Legale della Alienazioni Mentale, 83, 1-132.

Buge, A., Rancurel, G., Poisson, M., and Dechy, H. (1974a). Encéphalopathies myocloniques par les sels de bismuth. Six cas observés lors de traitements oraux au long cours. Nouvelle Presse Médicale, 3, 2315-2320.

Buge, A., Rancurel, G., Poisson, M., Gazengel, J., Dechy, H., Fressinaud, L., and Emile, J. (1974b). 20 observations d'encéphalopathies aigues avec myoclonies au cours de traitements oraux par les sels de bismuth. Annales de Médecine Interne, 125, 877-886.

Buge, A., and Rancurel, G. (1975). Les encéphalopathies aigues myocloniques par les sels oraux de bismuth. Revue de Médecine (Paris), 24, 1668-1674.

Burns, R., Thomas, W., and Barron, V. J. (1974). Reversible encephalopathy possibly associated with bismuth subgallate ingestion. British Medical Journal, 1, 220-223.

Escourolle, R., Hauw, J. J., Bourdon, R., Simon, P., Jaudon, M. C., and Gray, F. (1977). Etude neuropathologique et toxicologique de 13 cas d'encéphalopathie bismuthique. Revue Neurologique, 133, 153163.

Gaches, J. (1973). L'électroencéphalogramme dans les démences génétiques et transmissibles. 10th International Congress of Neurology, Barcelona. Excerpta Médica International Congress Series, 319, 339-47.

Gastaut, J. L., Tassinari, C. A., Terzano, G., and Picornell, I. (1975). Etude polygraphique de l'encéphalopathie myoclonique bismuthique. Revue EEG et Neurophysiologie Clinique, 3, 295-302.

Jones, D. P., and Nevin, S. (1954). Rapidly progressive cerebral degeneration (subacute vascular encephalopathy) with mental disorder, focal disturbances and myoclonic epilepsy. Journal of Neurology, Neurosurgery, and Psychiatry, 17, 148-159.

Letemendia, F., and Pampiglione, G. (1958). Clinical and electroencephalographic observations in Alzheimer's disease. Journal of Neurology, Neurosurgery, and Psychiatry, 21, 167-172.

Lhermitte, F., Degos, F., and Signoret, J. L. (1975). Encéphalopathies réversible par les sels insolubles de bismuth. Nouvelle Presse Médicale, 4, 419-420.

Loiseau, P., Henry, P., Jallon, P., Legroux, M., LatinVille, D., and Dangouman, J. (1975). Encéphalopathie iatrogène par les sels de bismuth. Concours Médical, 12, 2475-2478.

Martin-Bouyer, G. (1976). Intoxications par les sels de bismuth administrés par voie orale: résultat d'une enquête épidémiologique, pp. 1-29. INSERM, Division de la Recherche Médico-scciale. Section Maladies Transmissibles: Paris.

Morrow, A. W. (1973). Requests for reports; adverse reactions with bismuth subgallate. Medical Journal of Australia, 1, 912.

Pallis, C. A., and Spillane, J. D. (1957). A subacute progressive encephalopathy with mutism, hypokinesia, rigidity, and myoclonus. A clinical and pathological account of three cases. Quarterly Journal of Medicine, 26, 349-75.

Sollmann, T., and Seifter, J. (1939). The pharmacology of trimethyl bismuth. Journal of Pharmacology and Experimental Therapeutics, 67, 17-49. 